\title{
Growth fractions in breast cancers determined in situ with monoclonal antibody Ki-67
}

\author{
J GERDES, ${ }^{*}$ R J LELLE, $\dagger$ H PICKARTZ,* W HEIDENREICH, \\ R SCHWARTING, ${ }^{*}$ L KURTSIEFER,* G STAUCH, $\ddagger$ H STEIN*
}

From the *Institute of Pathology, Klinikum Steglitz, Free University Berlin, the †Department of Obstetrics and Gynaecology, Medical School, University of Hannover, and the $\ddagger$ Institute of Pathology, Hannover, Federal Republic of Germany

SUMMARY The growth fractions of 160 mammary carcinomas and 30 benign mammary lesions were determined in situ by immunostaining with the monoclonal antibody Ki-67. Benign lesions had a mean value of $3 \% \mathrm{Ki}-67$ positive cells, whereas the mean value of mammary carcinomas was $16 \cdot 6 \%$. A comparison of the mean values of $\mathrm{Ki}-67$ positive cells with the histological grade of the tumours showed a correlation between these two variables - that is, histological grade 1 showed $9 \%$, grade $216 \%$, and grade $326 \%$ proliferating cells.

Considering the individual $\mathrm{Ki}-67$ values in the different histological grades, it was evident that there was considerable scatter in the number of proliferating cells, so that the proliferation rates of grades 1, 2, and 3 overlapped each other. This indicates a dissociation between histological grade of malignancy and size of the growth fraction in most breast cancers. Follow up studies are needed to establish which of the two variables - that is, morphological degree of malignancy, or the proportion of Ki-67 positive cells-correlates better with response to treatment and survival in individual cases.

As breast cancer represents one of the most common tumours in the western hemisphere, reliable and reproducible prognostic variables need to be established. In the past the malignancy of a breast carcinoma was predominantly judged by morphological criteria such as the widely accepted tumour grading described by Bloom and Richardson. ${ }^{1}$ According to Schiodt, the number of mitotic figures is the most important variable for predicting prognosis in this type of tumour.

The monoclonal antibody $\mathrm{Ki}-67$, prepared by our group, ${ }^{3}$ reacts with a nuclear antigen present in proliferating cells but absent in quiescent cells. A detailed cell cycle analysis showed that the $\mathrm{Ki}-67$ antigen is expressed throughout the whole cell cycle, making the antibody suitable for the determination of the growth fraction of a benign or malignant human cell subset. ${ }^{4}$ We recently showed a highly significant correlation between the proportion of $\mathrm{Ki}-67$ positive cells and the histological classification of malignant nonHodgkin's lymphomas into high and low grade malignancies. ${ }^{5}$ Thus the determination of the growth fraction with $\mathrm{Ki}-67$ might be a new and reliable prognostic marker for these tumours.

The evaluation of cell kinetic data in mammary carcinomas should also be undertaken for tumour grading, as this can provide reproducible prognostic information.

This paper reports on the immunohistological determination of the growth fraction with $\mathrm{Ki}-67$ in a variety of breast tumours and compares the results with conventional histological grading.

\section{Material and methods}

Thirty benign mammary lesions and 160 mammary carcinomas from patients attending the gynaecology clinics at the Klinikum Steglitz, and the Medical School, Hannover, were studied. There were 148 invasive ductal carcinomas, nine invasive lobular carcinomas, three medullary carcinomas and no carcinomata in situ. Cryostat sections of biopsy specimens were immunostained with monoclonal antibody $\mathrm{Ki}-67$, which was prepared as previously described, ${ }^{3}$ according to the indirect three step immunoperoxidase method, ${ }^{6}$ or according to the alkaline phosphatase-antialkaline phosphatase (APAAP) 


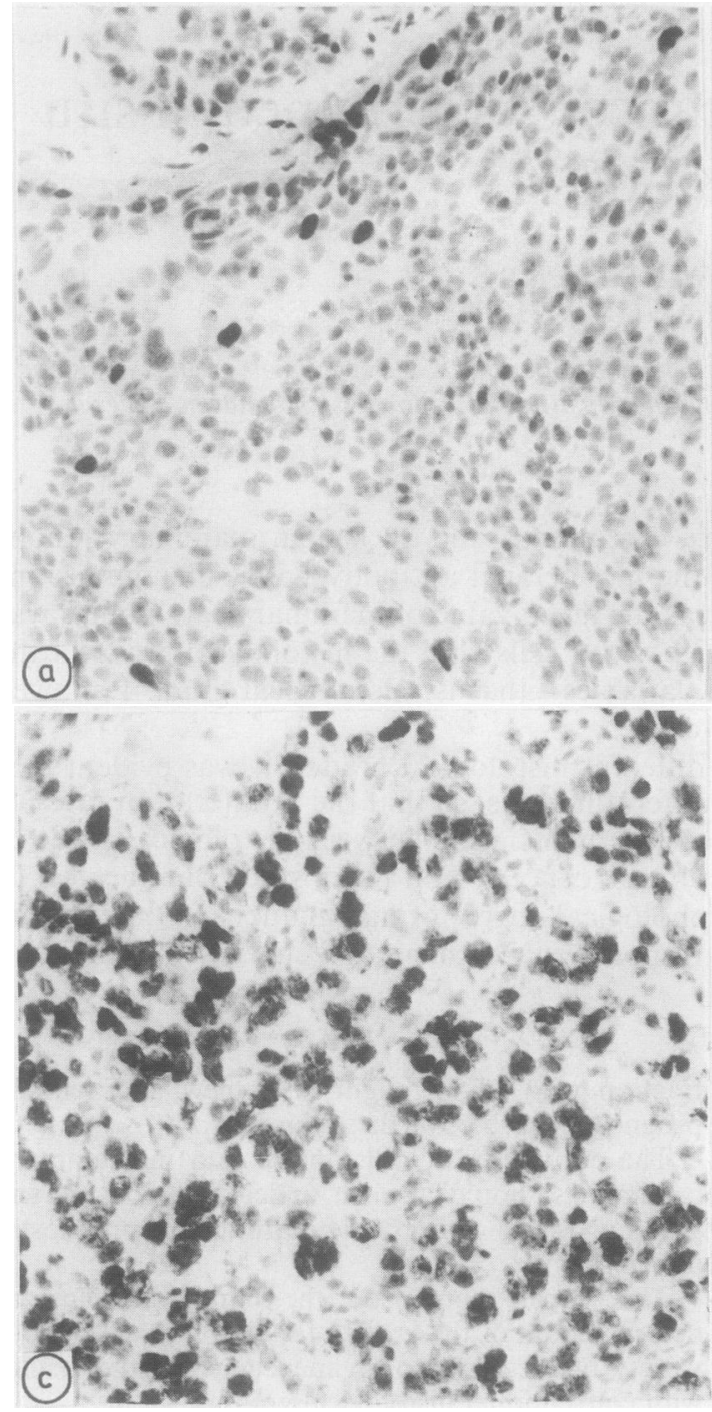

techniques. ${ }^{7}$

Histological grading was performed according to the method of Bloom and Richardson ${ }^{1}$ in routinely processed paraffin sections without previous knowledge of the growth fraction. Immunostaining reactions were evaluated, as described previously. ${ }^{5}$ Briefly, serial sections were immunostained with $\mathrm{Ki}-67$ and an antibody against cytokeratin (clone KL1, Dianova, Hamburg, Federal Republic of Germany). Cytokeratin staining was used to ensure that the fields of the biopsy had a characteristic infiltration of tumour cells. The percentage of $\mathrm{Ki}-67$ positive cells was determined at $\times \mathbf{4 0 0}$ magnification by counting $200-500$ cells in these fields.

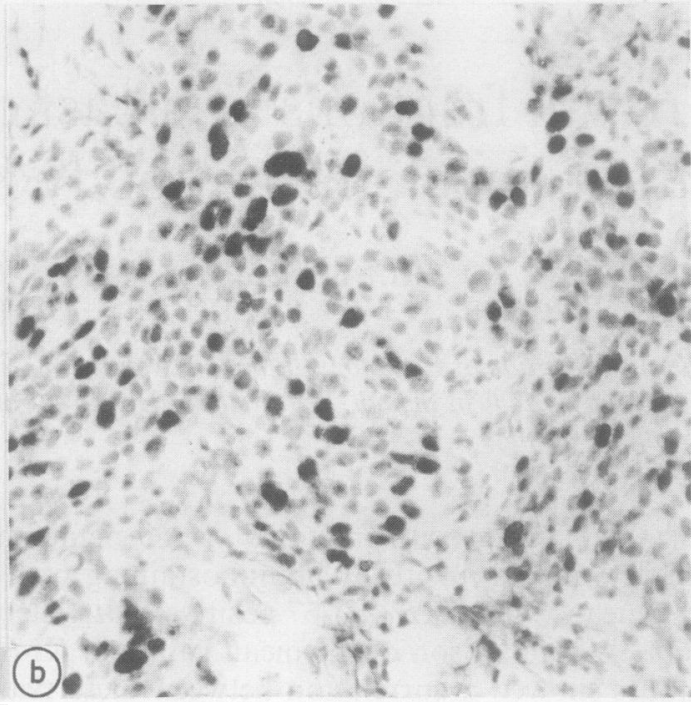

Fig 1 Immunostaining with Ki-67 of frozen tissue sections of mammory carcinomas. (a) Case with small growth fraction; (b) case with moderate growth fraction; (c) case with large growth fraction.

\section{8}

Statistical analysis was performed using Student's $t$ test.

\section{Results}

Fig 1 shows the characteristic immunostaining patterns obtained with $\mathrm{Ki}-67$, in cases with a small growth fraction (fig 1a), with a moderate growth fraction (fig 1b), and with a large growth fraction (fig 1c). Fig 2 summarises the results obtained by immunostaining of all benign and malignant mammary lesions.

The mammary carcinomas were additionally grouped according to their histological grade of 


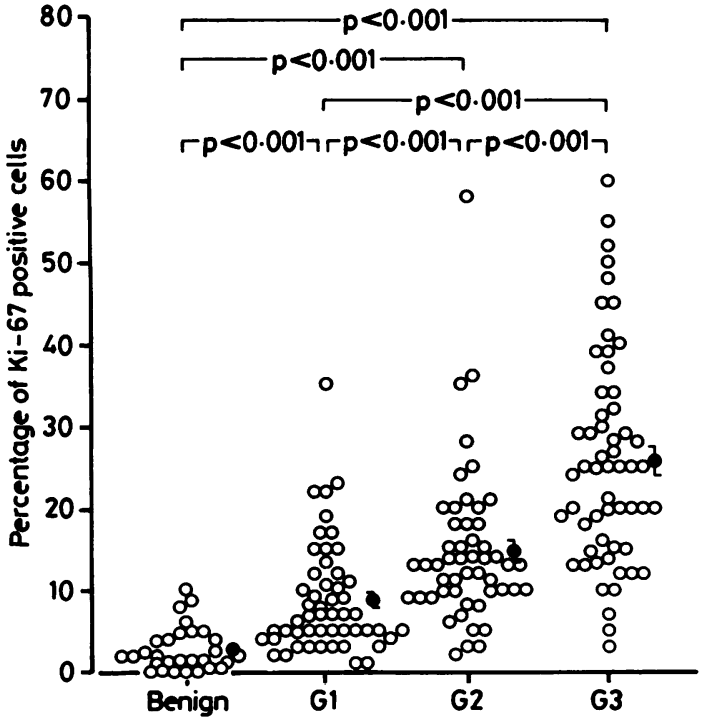

Fig 2 Growth fractions of 30 benign mammary lesions and 160 breast carcinomas determined by immunostaining frozen sections with the monoclonal antibody Ki-67: cases of mammary carcinoma were grouped according to their histological grade of malignancy. Open circles represent percentage of $\mathrm{Ki}-67$ positive cells of a single case; closed circles give mean value plus minus standard error.

Differences between groups were significant $(p<0-001)$.

malignancy. The benign cases had a mean value of $3 \% \mathrm{Ki}-67$ positive cells. The individual cases in this group had values of $<0.01$ to $10 \% \mathrm{Ki}-67$ positive cells. The mean value of mammary carcinomas, which had been histologically classified as grade 1 tumours, was $9 \%$. In this group values varied between 0.5 and $35 \%$. The grade 2 carcinomas had a mean value of $15 \% \mathrm{Ki}-67$ positive cells, ranging from 1 to $58 \%$. The mean value of the growth fractions of the grade 3 tumours was $26 \%$, and here, the cases varied from 3 to $60 \% \mathrm{Ki}-67$ positive cells. The differences between all these groups were significant (Student's $t$ test; $\mathrm{p}<$ 0.001 ) (fig 2).

Histological subtyping of mammary carcinomas showed that all invasive lobular tumours, classified as grade 1 carcinomas, had low to moderate growth fractions, whereas the medullary carcinomas (classified as grade 3 tumours all had more than $50 \%$ $\mathrm{Ki}-67$ positive cells.

\section{Discussion}

The results of this study show that there is a significant correlation between histological grading of mammary carcinomas and the mean values of the growth fractions, as determined by immunostaining with monoclonal antibody $\mathrm{Ki}-67$. This is not really surprising, as the number of mitoses and thus the proliferative capacity of a tumour is one of the most crucial variables for histological tumour grading. ${ }^{2}$

The counting of mitotic figures in routinely stained paraffin sections is difficult and time consuming. Furthermore, it has been shown that there is considerable subjective variation in histological tumour grading. ${ }^{89}$ The wide application of other methods to determine cell kinetic variables in mammary carcinomas, such as ${ }^{3} \mathrm{H}$-thymidine incorporation, ${ }^{1011}$ or flow cytometry, ${ }^{12}$ has been difficult, because these methods are time consuming or they require expensive equipment, or both. Immunohistological labelling with monoclonal antibody $\mathrm{Ki}-67$ is simple, well within the scope of routine surgical pathology laboratories, and might be a more objective aid for assessing the grade of malignancy.

Furthermore, our data show that the size of the growth fraction varies considerably from case to case within different histologically defined grades of malignancy. Apart from the subjective factors influencing the histological grading, these findings show that there is a considerable dissociation between histological grading and the size of the growth fraction in most cases of breast cancer, which is probably due to the fact that the histological grading includes not only a percentage of mitotic tumour cells but several other variables, such as glandular organisation of the tumour and grade of anaplasia. The question to be answered is which variables are more important in terms of prognosis.

In this context several studies have shown that there is an important correlation between the proliferative status of a given tumour and the patient's response to treatment and subsequent survival. ${ }^{101113-15}$ Furthermore, most cytostatic agents influence only those cells which proliferate. ${ }^{16}$ Thus it is difficult to recommend a combination of different variables to define a grade of malignancy before the value of the individual variables has been determined by appropriate studies. Follow up studies are needed to assess whether the determination of the growth fraction with $\mathrm{Ki}-67$ or histological tumour grading correlates better with response to treatment and survival in breast cancer. Such studies are now in progress.

This study was supported by the Deutsche Forschungsgemeinschaft Project Ge 504/1-1. We thank Gabi Burghardt, Heidrun Steeger, Iris-Ute Fricke, Sylvia Hattert, and Lothar Jaeschke for their excellent technical help.

\section{References}

1 Bloom HJG, Richardson WW. Histological grading and prognosis in breast cancer. Br J Cancer 1957;11(3):359-77. 
2 Schiodt T. Breast carcinomas-a histologic and prognostic study of 650 followed up cases. Copenhagen: Munksgaard, 1966.

3 Gerdes J, Schwab U, Lemke H, Stein H. Production of a mouse monoclonal antibody reactive with a human nuclear antigen associated with cell proliferation. Int J Cancer 1983;31:13-20.

4 Gerdes J, Lemke H, Baisch H, et al. Cell cycle analysis of a cell proliferation-associated human nuclear antigen defined by the monoclonal antibody Ki-67. J Immunol 1984;133:1710-5.

5 Gerdes J, Dallenbach F, Lennert K, et al. Growth fractions in malignant non-Hodgkin's Lymphomas (NHL) as determined in situ with the monoclonal antibody Ki-67. Hematol Oncol 1984;2:365-71.

6 Stein H, Gerdes J, Schwab U, et al. Identification of Hodgkin and Sternberg-Reed cells as a unique cell type derived from a newly-detected small cell population. Int J Cancer 1982; 30:445-9.

7 Cordell JL, Falini B, Erber WN, et al. Immunoenzymatic labeling of monoclonal antibodies using immune complexes of alkaline phosphatase and monoclonal anti-alkaline phosphatase (APAAP) complexes. J Histochem Cytochem 1984;32:219-29.

8 Cutler SJ, Black MM, Friedell RA, et al. Prognostic factors in cancer of the female breast. II. Reproducibility of histopathologic classification. Cancer 1966;19:75-83.

9 Stenquist B, Westmann-Naeser S, Vegelius J, et al. Analysis of reproducibility of subjective grading systems for carcinoma. J Clin Pathol 1979;32:979-85.
10 Tubiana M, Pejovic MJ, Renaud A, et al. Kinetic parameters and the coure of disease in breast cancer. Cancer 1981;47:937-43.

11 Meyer JS, Friedman E, McCrate MM, Bauer WC. Prediction of early course of breast carcinoma by thymidine labelling. Cancer 1983;51:1879-86.

12 Haag D, Goerttler K, Tschahargane. The proliferative Index (PI) of human breast cancer as obtained by flow cytometry. Path Res Pract 1984;178:315-22.

13 Meyer JS, Hixon B. Advanced stage and early relapse of breast carcinomas associated with high thymidine labeling indices. Cancer Res 1979;39:4042-7.

14 Meyer JS, Lee JY. Relationships of S-phase fraction of breast carcinoma in relapse to duration of remission, estrogen receptor content, therapeutic responsiveness, and duration of survival. Cancer Res 1980;40:1890-6.

15 Charlson ME, Feinstein AR. Rapid growth rate in breast cancer: a confounding variable in adjuvant-chemotherapy trials. Lancet 1982;i:1343-5.

16 Valeriote F, van Putten L. Proliferation-dependant cytotoxicity of anticancer agents: a review. Cancer Res 1975;35:2619-30.

Requests for reprints to: Dr Johannes Gerdes, Institute of Pathology, Klinikum Steglitz, Hindenburgdamm 30, D-1000 Berlin, Federal Republic of Germany. 